\title{
The earliest unequivocally modern humans in Southern China
}

Wu Liu ${ }^{1 *}$, María Martinón-Torres ${ }^{2,3,4 *}$, Yan-jun Cai ${ }^{5}$,Song Xing ${ }^{1}$, Hao-wen Tong ${ }^{1}$, Shu-wen Pei ${ }^{1}$, Mark Jan Sier ${ }^{6,7,4}$, Xiao-hong $\mathrm{Wu}^{8}$, R. Lawrence Edwards ${ }^{9}$, Hai Cheng $^{10}$, Yi-yuan $\mathrm{Li}^{11}$, Xiong-xin Yang ${ }^{12}$, José María Bermúdez de Castro ${ }^{4,2}$, Xiu-jie $\mathrm{Wu}^{1^{*}}$

1 Key Laboratory of Vertebrate Evolution and Human Origins of Chinese Academy of Sciences, Institute of Vertebrate Paleontology and Paleoanthropology, Chinese Academy of Sciences, Beijing 100044, China

2 UCL Anthropology, 14 Taviton Street, London, WC1H 0BW

3 Departamento de Ciencias Históricas y Geografía. University of Burgos. Hospital del Rey, s/n. 09001 Burgos, Spain

4 Centro Nacional de Investigación sobre la Evolución Humana (CENIEH), Burgos, Spain

5 State Key Laboratory of Loess and Quaternary Geology, Institute of Earth Environment, Chinese Academy of Sciences, Xian 710075, China

6 Paleomagnetic Laboratory 'Fort Hoofddijk', Department of Earth Sciences, Faculty of Geosciences, Utrecht University, Budapestlaan 17, $3584 \quad$ CD Utrecht, The Netherlands

7 Faculty of Archaeology, Leiden University, P.O. Box 9515, 2300 RA Leiden, The Netherlands

8 School of Archaeology and Museology, Peking University, Beijing 100871, China.

9 Department of Geology and Geophysics, University of Minnesota, Minneapolis, MN 55455

10 Institute of Global Environmental Change, Xi'an Jiaotong University, Xi'an 710049, China

11 Institute of Cultural Relics and Archaeology, Hunan Province, Changsha 410008, China

12 Cultural Relics Administration of Daoxian County, Daoxian 425300, China

13 *These authors contributed equally to this work

*Corresponding authors: M.M.T. (maria.martinon.torres@gmail.com), W.L. (liuwu@ivpp.ac.cn), X-J. W. (wuxiujie@ivpp.ac.cn) 
The hominin record from Southern Asia for the early Late Pleistocene is scarce. Presently, well-dated and well-preserved fossils older than $\sim 45$ kyr that can be unequivocally attributed to Homo sapiens are lacking ${ }^{1-4}$. Here we present evidence from the newly excavated Fuyan Cave in Daoxian (Southern China). This site has provided 47 human teeth dated to more than $80 \mathrm{kyr}$ and with an inferred maximum age of $120 \mathrm{kyr}$. The morphological and metric assessment of this sample supports its unequivocal assignment to $H$. sapiens. The Daoxian sample is more derived than any other anatomically modern humans, resembling middle-to-late Late Pleistocene specimens and even contemporary humans. Our study shows that fully modern morphologies were present in Southern China 30 to 70 kyr earlier than in the Levant and Europe ${ }^{5-7}$. Our data fills a chronological and geographical gap that is relevant for understanding when $H$. sapiens first appeared in Southern Asia. The Daoxian teeth also support the statement that during the same period, Southern China was inhabited by more derived populations than Central and Northern China. This evidence is important for the study of modern humans' routes of dispersals. Finally, our results are relevant to explore the reasons for the relatively late entry of $H$. sapiens into Europe. Some studies have investigated how the competition with $\boldsymbol{H}$. sapiens may have caused Neanderthals' extinction (for a revision see Villa and Roebroeks ${ }^{8}$ and references therein). Interestingly, despite fully modern humans were already present in Southern China at least as early as $\sim 80 \mathrm{kyr}$, there is no evidence that they entered Europe before $\sim 45 \mathrm{kyr}$. This could imply that $\boldsymbol{H}$. neanderthalensis was indeed an additional ecological barrier for modern humans, who could only enter Europe when Neanderthal's demise already started. 
The Fuyan Cave $\left(25^{\circ} 39^{\prime} 02.7^{\prime \prime} \mathrm{N}, 111^{\circ} 28^{\prime} 49.2^{\prime \prime} \mathrm{E} ; 232 \mathrm{~m}\right.$ above sea level) is located in Tangbei Village, Daoxian County, Hunan Province, Southern China (Fig. 1). It is part of a large multi-genesis pipeline type karst system which contains several connected and stacked caves (Supplementary Information A) and covers an area of over $3000 \mathrm{~m}^{2}$. The investigation and excavations were conducted at three regions in the cave, Region I, II and III (Extended Data Fig. 1). From 2011 to 2013, systematic excavations yielded forty-seven human teeth and an abundant fossil mammalian assemblage (Fig. 2 and Extended Data Fig. 2 and 3).

Four clear stratigraphic layers were consistently identified in the whole excavated regions (Region I, II and III), with a total thickness of more than $250 \mathrm{~cm}$ (Fig. 1). All the hominin and mammalian fossils were found in layer 2 of Region I (mammals) and Region II (mammals and humans), although three human teeth (DX1, DX2 and DX6) and a small amount of mammal fossils were found out of context as surface findings during the first year of excavation. The stratigraphic sequence of Region II, from top to bottom, is described as follows: 1) Layer 1: Continuous browngrey and brown-yellow flowstone/calcite-cemented deposit with a maximum thickness of $20 \mathrm{~cm}$; 2) Layer 2: Brown-yellow and grey thin sandy clay of 20-50 cm in thickness which contains large amount of mammal fossils and the hominin teeth; 3) Layer 3: Brown and grey sandy gravel of 80-100 cm in thickness; and 4) Layer 4: Grey-yellow and brown-yellow silt and clay with calcareous breccia imbedded. This layer is over 100 $\mathrm{cm}$ in thickness as the bottom has not been reached yet.

To present, no stone tools have been found. The hominin and most of the faunal elements consist exclusively of teeth, and many of them present root alterations mostly due to the effects of calcium dissolution and some rodent gnawing (Supplementary Information B). The mammal fossil assemblage from the Daoxian site is typical of Late 
Pleistocene in Southern China and is composed of 38 species including 5 extinct large mammals such as Ailuropoda baconi, Crocuta ultima, Stegodon orientalis, Megatapirus augustus, Sus sp. (Extended Data Table 1 and Supplementary Information C). The radiocarbon age $>43 \mathrm{kyr}$ cal $\mathrm{BP}$ obtained for one of the faunal remains (see Supplementary Information D) supports its pre-late Late Pleistocene age.

During the excavations, we collected 9 samples of speleothem fragments from Layer 2 to Layer 3 (FYS-1 to FYS-9) at Region I and Region II, and 2 subsamples (FYS-S1 to FYS-S2) from a small stalagmite that grew on the top of Layer 1 (Fig. 1, Extended Data Fig. 1 and Supplementary Information E). These samples were carefully preprocessed to single out the clean portion for ${ }^{230} \mathrm{Th}$ dating and then analyzed at the Isotope Lab of University of Minnesota using the MC-ICP-MS dating technique ${ }^{9}$. Eight speleothem fragments from Layer 2 yielded Middle to Late Pleistocene ages ranging from 556 kyr BP to $120.7 \mathrm{kyr}$ BP, and one sample collected from layer 3 (FYS-9) provided an age older than $600 \mathrm{kyr} \mathrm{BP}$ and thus, beyond the limit of ${ }^{230} \mathrm{Th}$ dating method) (Table 1). The two subsamples from the small stalagmite give an age of $80.1 \pm$ 1.2 kyr BP and 79.5 $\pm 2.8 \mathrm{kyr} \mathrm{BP}$, respectively.

The calcitic floor (Layer 1) is encrusted on Layer 2, and is continuous across the excavated regions, preventing younger material from being introduced into the underlying deposits (see Supplementary Cave Tour.ppt file). The abundant and extensive distribution of the fauna and the human teeth across the cave makes redeposition of Layer 2 highly unlikely. In addition, paleo- and rockmagnetic analysis of a sample Layer 1 at Region IIA confirms that the flowstone that caps the fossil-bearing Layer 2 remains in situ (Supplementary Information F and Extended Data Fig. 4). It means that the dated stalagmite was formed after the fossils were buried and it provides a minimum age constraint $(\sim 80 \mathrm{kyr})$ for the fossils below. Since the associated fauna is 


\begin{tabular}{|c|c|c|c|c|c|c|c|c|c|}
\hline Sample ID & $\begin{array}{l}\text { Region/ } \\
\text { Layer }\end{array}$ & $\begin{array}{l}{ }^{238} \mathrm{U} \\
(\mathrm{ppb})\end{array}$ & $\begin{array}{l}{ }^{232} \mathrm{Th} \\
(\mathrm{ppt})\end{array}$ & $\begin{array}{c}{ }^{230} \mathrm{Th} /{ }^{232} \mathrm{Th} \\
\left(\text { atomic } \times 10^{-6} \text { ) }\right.\end{array}$ & $\begin{array}{c}\delta^{234} U^{*} \\
\text { (measured) }\end{array}$ & $\begin{array}{c}{ }^{230} \mathrm{Th} /{ }^{238} \mathrm{U} \\
\text { (activity) }\end{array}$ & $\begin{array}{c}{ }^{230} \mathrm{Th} \text { Age } \\
\text { (kyr BP) } \\
\text { (uncorrected) }\end{array}$ & $\begin{array}{c}\delta^{234} \mathrm{U}_{\text {Initial }}{ }^{* *} \\
\text { (corrected) }\end{array}$ & $\begin{array}{l}{ }^{230} \mathrm{Th} \text { Age } \\
\text { (kyr BP)**** } \\
\text { (corrected) }\end{array}$ \\
\hline FYS-S1 & IID/ layer 1 & $133.3 \pm 0.3$ & $9117 \pm 183$ & $176.5 \pm 3.6$ & $353.1 \pm 4.5$ & $0.7326 \pm 0.0033$ & $81.5 \pm 0.7$ & $443 \pm 6$ & $80.1 \pm 1.2$ \\
\hline FYS-S2 & IID/ layer 1 & $285.9 \pm 0.4$ & $55026 \pm 1102$ & $64.0 \pm 1.3$ & $356.2 \pm 3.2$ & $0.7467 \pm 0.0026$ & $83.4 \pm 0.5$ & $446 \pm 5$ & $79.5 \pm 2.8$ \\
\hline FYS-1 & IIA/ layer 2 & $428.2 \pm 0.7$ & $98699 \pm 1976$ & $59.4 \pm 1.2$ & $54.3 \pm 2.1$ & $0.8302 \pm 0.0017$ & $164.7 \pm 1.2$ & $85 \pm 3$ & $158.3 \pm 4.6$ \\
\hline FYS-2 & IIA/ layer 2 & $10747.9 \pm 69.1$ & $27564 \pm 552$ & $7463.3 \pm 149.9$ & $633.0 \pm 4.2$ & $1.1609 \pm 0.0077$ & $121.0 \pm 1.5$ & $891 \pm 7$ & $121.0 \pm 1.5$ \\
\hline FYS-3 & IC/ layer 2 & $126.0 \pm 0.2$ & $8675 \pm 174$ & $263.5 \pm 5.3$ & $75.6 \pm 2.5$ & $1.1000 \pm 0.0027$ & $558.3 \pm 62.8$ & $364 \pm 67$ & $556.8 \pm 61.9$ \\
\hline FYS-4 & IB/ layer 2 & $1608.5 \pm 5.5$ & $889 \pm 18$ & $29237 \pm 588$ & $401.0 \pm 3.5$ & $0.9800 \pm 0.0035$ & $120.7 \pm 0.9$ & $564 \pm 5$ & $120.7 \pm 0.9$ \\
\hline FYS-5 & IB/ layer 2 & $260.0 \pm 0.4$ & $41356 \pm 828$ & $122.7 \pm 2.5$ & $173.3 \pm 2.7$ & $1.1837 \pm 0.0026$ & $351.5 \pm 8.1$ & $463 \pm 13$ & $348.3 \pm 8.2$ \\
\hline FYS-6 & IA/ layer 2 & $120.6 \pm 0.2$ & $81358 \pm 1629$ & $22.6 \pm 0.5$ & $171.4 \pm 2.7$ & $0.9236 \pm 0.0027$ & $158.5 \pm 1.4$ & $256 \pm 10$ & $141.8 \pm 12.1$ \\
\hline FYS-7 & IID/ layer 2 & $87.4 \pm 0.1$ & $12302 \pm 246$ & $120.3 \pm 2.5$ & $187.8 \pm 5.1$ & $1.0276 \pm 0.0055$ & $196.1 \pm 3.8$ & $324 \pm 10$ & $192.9 \pm 4.3$ \\
\hline FYS-8 & IID/ layer 2 & $78.4 \pm 0.2$ & $20571 \pm 413$ & $55.2 \pm 1.1$ & $157.4 \pm 7.7$ & $0.8786 \pm 0.0044$ & $147.1 \pm 2.7$ & $234 \pm 12$ & $140.7 \pm 5.2$ \\
\hline FYS-9 & IIC/ layer 3 & $267.6 \pm 0.4$ & $20907 \pm 419$ & $10618.9 \pm 226.1$ & $147.6 \pm 3.2$ & $2.5165 \pm 0.3707$ & $>600$ & -- & -- \\
\hline
\end{tabular}

$* \delta^{234} \mathrm{U}=\left(\left[{ }^{234} \mathrm{U} /{ }^{238} \mathrm{U}\right]_{\text {activity }}-1\right) \times 1000 . * * \delta^{234} \mathrm{U}_{\text {initial }}$ was calculated based on ${ }^{230} \mathrm{Th}$ age $(\mathrm{T})$, i.e., $\delta^{234} \mathrm{U}_{\text {initial }}=\delta^{234} \mathrm{U}_{\text {measured }} \times \exp \left(\lambda_{234} \times \mathrm{T}\right) . \quad{ }^{* * *} \mathrm{Corrected}{ }^{230} \mathrm{Th}$ ages assume the initial ${ }^{230} \mathrm{Th} /{ }^{232} \mathrm{Th}$ atomic ratio of $4.4 \pm 2.2 \times 10^{-6}$. Those are the values for a material at secular equilibrium, with the bulk earth ${ }^{232} \mathrm{Th} /{ }^{238} \mathrm{U}$ value of 3.8 . The errors are arbitrarily assumed to be $50 \%$. BP stands for "Before Present" where the "Present" is defined as the year 1950 A.D 
typical of the Late Pleistocene we conservatively assume that fossils are not older than $\sim 120 \mathrm{kyr}$, and the presence of hominins at Daoxian can be bracketed between 80-120 kyr.

Daoxian teeth were compared to large dental samples of Late Pleistocene hominin fossils from Europe, Africa and Asia (Extended Data Table 2 and 3 and Supplementary Information $\mathrm{G}$ and $\mathrm{H}$ ). The Daoxian teeth are small and they consistently fall within H. sapiens variability (Fig. 3 and Extended Data Fig. 5). They are generally smaller than other Late Pleistocene specimens from Africa and Asia and closer to European Late Pleistocene samples and contemporary modern humans. Both the crown and the root of Daoxian teeth show typical morphologies for H. sapiens (Fig. 2 and Extended Data Fig. 6) with simplified occlusal and labial/buccal surfaces and short and slender roots. The presence of moderate basal bulging as well as longitudinal grooves in the buccal surface of canines, premolars and molars from other Late Pleistocene samples like Xujiayao, Huanglong Cave, Qafzeh or Dolni Vestonice make Daoxian teeth morphologically closer to middle-to-late Late Pleistocene and even contemporary human samples (Extended Data Fig. 6). Canine and molar roots are gracile and barely divergent, differing from the stout and robust root systems of Tubo or Xujiayao localities ${ }^{10}$ where radicals do not narrow towards the tip (Extended Data Fig. 6). Indeed, the convergent apices of the molar buccal roots appear as a typical feature in contemporary $H$. sapiens. $\mathrm{M}^{1} \mathrm{~s}$ are also typical of $H$. sapiens and unlike the rhomboidal contour displayed by $H$. neanderthalensis ${ }^{11}$ or the buccolingually elongated shape of Asian H. erectus ${ }^{12-14}$. The relative cusp and occlusal polygon areas of the Daoxian $\mathrm{M}^{1} \mathrm{~s}$ follow the $H$. sapiens pattern and they only differ from $0.6 \%$ to $1.1 \%$ from modern Chinese populations (Extended Data Table 4). Interestingly, Qafzeh $\mathrm{M}^{1} \mathrm{~s}$ are comparatively less derived than Daoxian, showing a departure from the typical $H$. 
sapiens pattern of cusp proportions and angles as it was previously noticed by Bailey ${ }^{11}$.The occlusal morphology of Daoxian $\mathrm{M}^{2}$ and $\mathrm{M}^{3} \mathrm{~s}$ is also simple, and both the metacone and the hypocone are strongly reduced as it is typical of $H$. sapiens. The lack of labial convexity, shovel shape and tuberculum dentale, as well as the gracile root of the Daoxian $\mathrm{I}_{2}$ resemble that of contemporary and Late Pleistocene $H$. sapiens and differs from Neanderthals. However, Dolni Vestonice specimens display higher labial convexity, and Qafzeh and Huanglong Cave $\mathrm{I}_{2} \mathrm{~S}$ present a more prominent basal eminence, making Daoxian $\mathrm{I}_{2}$ closer to contemporary humans rather than other Late Pleistocene samples. The two Daoxian $\mathrm{P}_{3}$ s show a slightly asymmetric oval contour due to the disto-lingual projection of a small platform-like talonid without accessory cusps. Overall, the crown morphology together with the expression of a slender single root of Daoxian $\mathrm{P}_{3} \mathrm{~S}$ is closer to $H$. sapiens and differs from the typical Neanderthal conformation, with compressed and centered occlusal polygon and lingually displaced metaconid $^{15}$. Lower molars lack the typically Neanderthal combination of a pit-like anterior fovea with a continuous mid-trigonid crest $^{16,17}$. This, together with the reduction of the hypoconulid and the expression of an X-pattern in all the $\mathrm{M}_{2}$ and $\mathrm{M}_{3}$ where this feature could be recorded make Daoxian lower molars morphologically closer to anatomically and contemporary modern humans ${ }^{18}$. In addition, no signs of taurodontism are present. Finally, the occlusal morphology of the two $\mathrm{dm}^{2} \mathrm{~s}$ from Daoxian is simple, and the occlusal outline relatively squared and unlike the typical skewed contour of Neanderthals. Roots are thin and diverge as it is typical in deciduous teeth and similar to the patterns usually found in fossil and contemporary $H$. sapiens. Thus, the morphological and metric comparison of the Daoxian dental sample allows its unequivocal attribution to $H$. sapiens, and they present particular resemblances to late Late Pleistocene samples and contemporary modern humans. 
Currently, the earliest unambiguous evidence of H. sapiens fossils east-ward of the Arabian Peninsula would come from Tianyuan Cave, in Northern China ${ }^{19}$, Niah Cave in Borneo ${ }^{4}$ and Lake Mungo in Australia ${ }^{20}$ dated to $\sim 40-50 \mathrm{kyr}$. The retention of primitive features in Qafzeh and Skhul, has been interpreted by many as evidence of a "failed" dispersal ${ }^{21,22}$ and several studies have recently suggested that an earlier and southern route may have been indeed more favorable for hominin expansion ${ }^{2,23-25}$. However, these and other related hypotheses were lacking the support of clear evidence of modern human occupation outside Africa (excluding the Levant) during the early Late Pleistocene. The fragmentary nature and/or the mosaic of modern and archaic features of remains like those from the Zhiren Cave have prevented a unanimous acceptance of its taxonomic status ${ }^{1,26}$. This, together with the contested chronologicalstratigraphic frame of some of the Asian hominin findings (see Dennell ${ }^{2}$ for a review), make the Daoxian teeth the earliest and soundest evidence of definitely modern humans in Southern China at least $80 \mathrm{kyr}$ ago. The Daoxian evidence may finally break the "quarantine" which most hypotheses considering the presence of $H$. sapiens in the early Late Pleistocene in China have been subjected to.

While Daoxian would testify the presence of fully modern populations in Southern China during the early Late Pleistocene, the Xujiayao ${ }^{10}$ and Denisova evidence $^{27}$ points to significantly more primitive hominins in the northern latitudes. Similarly, the dental morphology of the late Middle Pleistocene hominin from Panxian Dadong, in Southern China already exhibits some derived features ${ }^{28}$ that are absent in other roughly contemporaneous Asian populations of higher latitudes like those from Zhoukoudian, Hexian or Chaoxian ${ }^{10}$. This evidence could support different origins and/or routes of dispersals for the humankind across Asia ${ }^{23,24}$. 
Finally, while fully modern humans succeeded to disperse throughout Asia during the early Late Pleistocene, they failed to do so in Europe until 35 to 75 kyr later. Thus, we should not rule out the possibility that $H$. neanderthalensis was for a long time an additional barrier for modern humans' expansion, who could only settle in Europe when Neanderthal populations started to fade.

\section{References}

1 Dennell, R. Early Homo sapiens in China. Nature 468, 512-513 (2010).

2 Dennell, R. in Southern Asia, Austalia and the search for human origins (eds R. Dennell \& M. Porr) 33-50 (Cambridge University Press, 2014).

3 Storm, P. et al. U-series and radiocarbon analyses of human and faunal remains from Wajak, Indonesia. Journal of Human Evolution 64, 356-365, doi:http://dx.doi.org/10.1016/j.jhevol.2012.11.002 (2013).

4 Barker, G. et al. The 'human revolution' in lowland tropical Southeast Asia: the antiquity and behavior of anatomically modern humans at Niah Cave (Sarawak, Borneo). Journal of Human Evolution 52, 243-261, doi:http://dx.doi.org/10.1016/j.jhevol.2006.08.011 (2007).

5 Hershkovitz, I. et al. Levantine cranium from Manot Cave (Israel) foreshadows the first European modern humans. Nature 520, 216-219.

6 Grine, F. E. et al. Late Pleistocene human skull from Hofmeyr, South Africa, and modern human origins. Science 315, 226-229 (2007).

7 Benazzi, S. et al. The makers of the Protoaurignacian and implications for Neandertal extinction. 23 April 2015: science.aab0234v1-aab0234 (2015). 
8 Villa, P. \& Roebroeks, W. Neandertal demise: an archaeological analysis of the modern human superiority complex. PLoS ONE DOI: 10.1371/journal.pone.0096424 (2014).

9 Cheng, H. et al. Improvements in ${ }^{230} \mathrm{Th}$ dating, ${ }^{230} \mathrm{Th}$ and ${ }^{234} \mathrm{U}$ half-life values, and U-Th isotopic measurements by multi-collector inductively coupled plasma mass spectometry. Earth and Planetary Science Letters 371-372, 82-91 (2013).

10 Xing, S., Martinón-Torres, M., Bermúdez de Castro, J. M., Wu, X. \& Liu, W. Hominin teeth from the early Late Pleistocene site of Xujiayao, Northern China. American Journal of Physical Anthropology 156, 224-240, (2015).

11 Bailey, S. E. A morphometric analysis of maxillary molar crowns of MiddleLate Pleistocene hominins. Journal of human evolution 47, 183-198 (2004).

12 Xing, S. et al. Middle Pleistocene hominin teeth from Longtan Cave, Hexian, China. PLoS ONE 9(12), 3114265 doi:3114210.3111371/journal.pone.0114265 (2014).

13 Kaifu, Y. Advanced dental reduction in Javanese Homo erectus. Anthropological Science 114, 35-43 (2006).

14 Kaifu, Y. et al. Taxonomic Affinities and Evolutionary History of the Early Pleistocene Hominids of Java: Dentognathic Evidence. American Journal of Physical Anthropology 128, 709-726 (2005).

15 Gómez-Robles, A. et al. Geometric morphometric analysis of the crown morphology of the lower first premolar of hominins, with special attention to Pleistocene Homo. Journal of Human Evolution 55, 627-638, doi:DOI: 10.1016/j.jhevol.2008.03.011 (2008).

16 Bailey, S. E. Neandertal dental morphology: implications for modern human origins $\mathrm{PhD}$ thesis, Arizona State University, (2002). 
17 Martinón-Torres, M., Bermúdez de Castro, J. M., Gómez-Robles, A., PradoSimón, L. \& Arsuaga, J. L. Morphological description and comparison of the dental remains from Atapuerca-Sima de los Huesos site (Spain). Journal of Human Evolution 62, 7-58 (2012).

18 Martinón-Torres, M. et al. Dental evidence on the hominin dispersals during the Pleistocene. Proceedings of the Natural Academy of Science USA 104, 1327913282 (2007).

19 Shang, H. \& Trinkaus, E. The early modern human from Tianyuan Cave, China. (College Station TX: Texas A\&M University Press, 2010).

20 Bowler, J. M. et al. New ages for human occupation and climatic change at Lake Mungo, Australia. Nature 421, 837-840 (2003).

21 Mellars, P. Why did modern human populations disperse from Africa ca. 60,000 years ago? A new model. Proceedings of the National Academy of Sciences 103, 9381-9386, doi:10.1073/pnas.0510792103 (2006).

22 Oppenheimer, S. The great arc of dispersal of modern humans: Africa to Australia. Quaternary International 202, 2-13 (2009).

23 Armitage, S. J. et al. The Southern Route "Out of Africa": evidence for an early expansion of modern humans into Arabia. Science 331, 453-456 (2011).

24 Reyes-Centeno, H. et al. Genomic and cranial phenotype data support multiple modern human dispersals from Africa and a southern route into Asia. Proceedings of the National Academy of Sciences 111, 7248-7253 (2014).

25 Westaway, K. E. et al. Age and biostratigraphic significance of the Punung Rainforest Fauna, East Java, Indonesia, and implications for Pongo and Homo. Journal of Human Evolution 53, 709-717(2007). 
26 Liu, W., et al. Human remains from Zhirendong, South China, and modern human emergence in East Asia. Proceedings of the National Academy of Sciences 107, 19201-19206 (2010).

27 Reich, D. et al. Genetic history of an archaic hominin group from Denisova Cave in Siberia. Nature, 468, 1053-1060 (2010).

28 Liu, W. et al. Late Middle Pleistocene hominin teeth from Panxian Dadong, South China. Journal of Human Evolution 64, 337-355.

29 Scott, G. R. \& Turner, C. G. The Anthropology of Modern Human Teeth: Dental Morphology and its Variation in Recent Human Populations., (Cambridge University Press, 1997).

30 Weidenreich, F. The dentition of Sinanthropus pekinensis: a comparative odontography of the hominids. Palaeontologia Sinica New Series D 1, 1-180 (1937).

Supplementary Information is available in Supplementary Information. pdf

\section{Acknowledgements}

This work has been supported by the grants from Chinese Academy of Sciences (KZZD-EW-03, XDA05130101, GJHZ201314), National Natural Science Foundation of China (41272034, 41302016, 41271229), Netherlands Organisation for Scientific Research (NWO-ALW 823.01.003), Dirección General de Investigación of the Spanish Ministerio de Educación y Ciencia (CGL2009-12703-C03-01, 02 and 03, and Acción Integrada España Francia HF2007-0115), and Consejería de Educación de Junta de Castilla y León (CEN074A12-2) and Leakey Foundation (through the support of Mr. Gordon Getty and Mr. Dub Crook). We are grateful to several people who have 
provided access to comparative materials and/or advice in several aspects of the manuscript: Ruth Blasco, Jordi Rosell, Josep María Parés, Manuel Salesa, Andoni Tarriño, Carlos Saiz, Israel Hershkovitz, Amèlie Vialet, Marie Antoinette de Lumley, Cristina Bernís, Josefina Rascón and Jiri Svoboda. We are also grateful to Yu-shan Lou, Li-min Zhang and Pian-pian Wei who participated in the excavations at the Daoxian site.

Authors' contribution: X-J. W, W.L. and M.M.T. are the corresponding authors and have contributed equally to this work. X-J. W. and W.L. are directing the Daoxian research project. W. L., M.M.T., S. X., X-J. W. and J.M.BdC. performed the anthropological study of the Daoxian human teeth. Y-J. C. and S-W. P. conducted the geological studies of the Daoxian site. Y-J. C., R.L.E. and H. C. conducted the U-Th dating of the samples of the speleothems and stalagmite collected from the cave. M. J. S. conducted the paleomagentic analysis. X-H. W. conducted the radio carbon dating. H-W. T. conducted the study of the faunal remains. X-J. W., X-X. Y., Y-Y. L., W.L., Y-J. C., H-W. T. and S-W. P. participated in the field research.

Authors' information: Corresponding authors declare that the authors have no competing interests as defined by Nature Publishing Group, or other interests that might be perceived to influence the results and/or discussion reported in this article.

\section{Main legends}

Figure 1. Geographical location and stratigraphy of the Daoxian site. (a) Location of the Daoxian site. Late Middle Pleistocene and Late Pleistocene localities with human remains that have been included in the morphological and/or metric comparison with Daoxian are also marked in the map; (b) General view of the interior of the cave and the 
spatial relationship of Region IIA, IIB and IIC with some of the layers marked. (c) Plan view of the excavation area; (d) Detail of the stratigraphic layers of Region II of the Daoxian site. All human fossils come from Layer 2. 2: Tianyuan Cave; 3: Huanglong Cave; 4: Liujiang, 5: Zhiren Cave, 6: Tubo; 7: Xujiayao; 8: Luna; 9: Chuandong; 10: Malu Cave, 11 Lijiang, 12: Longlin; 13: Huli Cave, 14: Xintai. Map is adapted from the original Chinese map from National Administration of Surveying, Mapping and Geoinformation of China (http://219.238.166.215/mcp/index.asp).

Figure 2. Daoxian human teeth (selection). Please refer to Extended Data Table 2 for detailed information about each tooth (o: occlusal, b: buccal, l: lingual, m: mesial, d: distal). Credits: X. S., X-J. W.

Figure 3. Metric comparison of Daoxian teeth. Bivariate plots of the MD and BL dimensions of the Daoxian $\mathrm{P}^{3}$, lower cannine, $\mathrm{P}_{3}$ and $\mathrm{M}_{2}$.

\section{Table 1. The ${ }^{230}$ Th dating result of the Daoxian site.}

\section{Methods}

Description of the morphological features of the Daoxian hominin teeth follow the terminology usually employed in dental studies ${ }^{17,29,30}$. To assess the morphological affinities of Daoxian teeth we compared them to other Late Pleistocene samples from Africa, Asia and Europe (including Neanderthals), as well as a large contemporary $H$. sapiens sample (see Extended Data Table 3). Apart from both the descriptive comparative anatomy and the mesiodistal (MD) and buccolingual (BL) comparison, in the case of the $\mathrm{M}^{1}$ we also calculated the relative cusp and occlusal polygon size. 
For the metric comparison, the crown MD and BL dimensions of the Daoxian teeth were measured with a standard sliding caliper and recorded to the nearest $0.1 \mathrm{~mm}$. Bi-variate plots of the MD and BL diameters will be provided for the metric comparison of Daoxian with other hominin samples. In order to explore the Daoxian hominins in the context of the Middle to Late Pleistocene evolutionary changes in China, some Middle Pleistocene hominins from China were also included.

In addition, the total crown area and relative cusp area, and relative polygon areas for upper first molars were also measured and compared to a modern Chinese population. These features are considered to be taxonomically discriminative, particularly between $H$. sapiens and $H$. neanderthalensis ${ }^{11}$. The protocols for the measurement and calculation of the relative cusp areas of $\mathrm{M}^{1}$ can be found in Bailey $(2004)^{11}$

\section{Extended Data references}

\section{References}

31 Li, Y. et al. A preliminary report on the 2011 excavation at Houbeishan Fuyan Cave, Daoxian, Hunan Province. Acta Anthropol Sinica 32, 133-143 (2013).

32 Wu, X. Z. Yunxi Man: Excavation Report of the Huanglong Cave., (Science Press, 2006).

33 Jin, C. Z. et al. The Homo sapiens cave hominin site of Mulan Mountain, Jiangzhou District, Chongzhou, Guanxi with emphasis on its age. Chin Sci Bull 54, 3848-3856 (2009).

34 Yi, G. Liujian Man. Fossils 2, 15 (1982). 
35 Woo, J. Human fossils found in Kiukiang, Kwangsi, China. Paleovertebrata Paleoanthropologica 1, 97-104 (1959).

36 Molnar, S. Human tooth wear, tooth function and cultural variability. American Journal of Physical Anthropology 34, 175-190 (1971).

37 White, T. D. et al. Pleistocene Homo sapiens from Middle Awash, Ethiopia. Nature 423, 742-747 (2003).

38 Rightmire, G. P. \& Deacon, H. J. New human teeth from Middle Stone Age deposits at Klasies River, South Africa. Journal of Human Evolution 41, 535$544(2001)$.

39 Bräuer, G. \& Mehlman, M. J. Hominid molars from a Middle Stone Age level at the Mumba Rock Shelter, Tanzania. American Journal of Physical Anthropology 75, 69-76 (1988).

40 Chia, L. Note on the human and some other mammalian remains from Chgyang, Hupei. Vertebrata PalAsiatica 1, 247-257 (1957).

41 He, J. Preliminary study on the teeth of Jinniushan arcahic Homo sapiens. Acta Anthropol Sinica 19, 216-224 (2000).

$42 \mathrm{Wu}, \mathrm{M}$. New discoveries of human fossils in Tongzi, Guizhou. Acta Anthropol Sinica 3, 195-201 (1984).

43 Wu, M., Wang, L., Zhang, Y. \& Zhang, S. Fossil human teeth and associated cultural relics from Tongzi, Guizhou Province. Vertebrata PalAsiatica 13, 14-23 (1975).

44 Bae, C. J. et al. Modern human teeth from Late Pleistocene Luna Cave (Guangxi, China). Quaternary International 354, 169-183, doi:http://dx.doi.org/10.1016/j.quaint.2014.06.051 (2014). 
45 Chen, D. \& Qi, G. Fossil human and associated mammalian fauna found from Xizhou, Yunnan. Vertebrata PalAsiatica 16 (1978).

46 Dong, X. \& Fan, X. Note on human fossil teeth from Fox Cave at Qingliu. Acta Anthropologica Sinica 15, 315-319 (1996).

$47 \mathrm{Gu}, \mathrm{Y}$. in Selected Papers in Paleoanthropology (ed. Institute of Vertebrate Paleontology and Paleoanthropology) 158-171 (Science Press, 1978).

48 Huang, S. \& Zheng, L. The upper Pleistocene human tooth and mammalian fossil from Changwu, Xhaanxi. Acta Anthropol Sinica 1, 14-17 (1982).

49 Li, Y., Wu, M., Peng, S. \& Zhou, S. Human tooth fossils and some mammalian remains from Tubo, Liujiang, Guangxi. Acta Anthropol Sinica 3, 322-329 (1984).

50 Li, Y., Wu, M., Peng, S. \& Zhou, S. Preliminary report on the investigation of Dingmo Cave in Tiandong County, Guangxi. Acta Anthropol Sinica 4, 127-131 (1985).

51 Peng, S. \& Wang, W. Fossil of human beings and mammal discovered in Longdong Cave at Longlin, Guangxi. Ethnoarchaeology of South China 3, 187$292(1990)$.

52 Wang, W., Huang, Q. \& ZHou, S. New found human tooth fossils in Tubo, Guangxi. Longgupo Prehistory Culture 1, 104-108 (1999).

53 Wang, W. \& Mo, J. Human fossil teeth newly discovered in Nanshan Cave of Fusui, Guangxi. Acta Anthropol Sinica 23, 130-136 (2004).

54 Wang, W., Huang, C., Xie, S. \& Yan, C. Late Pleistocene hominin teeth from the Jimuyan Cave, Pingle County, Guangxi, South China. Quaternary Sciences 31, 699-704 (2011). 
55 Wu, X. Z., Zhao, Z., Yuan, Z. \& Shen, J. Report on paleoanthropological expedition of the Northeastern part of Kwangsi. Vertebrata PalAsiatica 6, 408413 (1962).

56 Wu, X. \& Zong, G. A human tooth and mammalian fossils of Late Pleistocene in Wuzhutai, Xintai, Shantong. Vertebrata PalAsiatica 11, 105-106 (1973).

$57 \mathrm{Yu}$, J. Fossil man and cultural artifacts from Chuandong, Puding County, Guizhou Province. Journal of Nanjing University (Natural Science) 20, 145-155 (1984).

58 You, Y., Dong, X., Chen, C. \& Fan, X. A fossil human tooth from Qingliu, Fujian. Acta Anthropol Sinica 8, 197-202 (1989).

59 Zheng, L. A fossil human tooth from Zhaotong, Yunnan. Acta Anthropol Sinica 4, 105-108 (1985).

60 Zhou, G. \& Yi, G. On the remains from Liuzhou region, Guangxi. Memoirs of Beijing natural History museum 20, 1-21 (1983).

61 Sládek, V., Trinkaus, E., Hillson, S. W. \& Holiday, T. W. The People of the Pavlovian: skeletal catalogue and osteometrics of the Gravettian Fossil hominids from Dolní Vestonice and Pavlov (2000).

62 Bailey, S. E., Glantz, M., Weaver, T. D. \& Viola, B. The affinity of the dental remains from Obi-Rakhmat Grotto, Uzbekistan. Journal of Human Evolution 55, $238-248(2008)$.

63 Quam, R., Bailey, S. E. \& Wood, B. A. Evolution of $\mathrm{M}^{1}$ crown size and cusp proportions in the genus Homo. Journal of Anatomy 214, 655-670 (2009).

\section{Extended data legends}


Extended Data Figure 1. The Daoxian site. Entrance to the Fuyan (Daoxian) cave (a). Image of the intact flowstone in an unexcavated area (b). Detail of the excavation at Region II C (c): Pink flags point to in situ human findings. Detail of the stratigraphy of Region IIA (d), IIB (e), IIC (f) and IID (g). In the center, plan view of the excavation area at the Daoxian Cave. The enlarged area shows the individual location of each human finding. Each picture provides a detail of the location of each dating sample. FYS: speleothem fragment samples. FYS-S: stalagmite samples. For more details on the U-series results see Table 1 and Supplementary Information E.

Extended Data Figure 2. Daoxian upper teeth. Please refer to Extended Table 2 for detailed information (o: occlusal, b: buccal, l: lingual, m: mesial, d: distal).

Extended Data Figure 3. Daoxian lower teeth. Please refer to Extended Data Table 2 for detailed information (o: occlusal, b: buccal, l: lingual, m: mesial, d: distal).

Extended Data Table 1. List of faunal composition at Daoxian and other Late Pleistocene localities of South China. Extinct species are marked in bold.

Extended Data Figure 4. Paleo- and rock- magnetic analysis of Daoxian flowstone. (a) Location of the orientated handsamples. White arrow indicates sample D1, black arrow indicates sample D2. (b) Zijderveld diagram of alternating field (AF) demagnetized specimen D1A. Numbers next to the graph denote AF step in mT. (c) Isothermal Remanent Magnetization (IRM) acquisition curve up to 1T for specimens D1A and D2D (d) Progressive stepwise thermal demagnetization of an IRM up to 1T of specimen D1A (e) Projection of virtual geomagnetic pole (VGP) of sample D1 with 
associated $\alpha 95$. (f) Table I summary table of Thermal (TH) and alternating field (AF) and hybrid (both $\mathrm{AF}$ and $\mathrm{TH}$ ) palaeomagnetic results. ID\#: sample identification; Demag Type (AF, TH or hybrid); NRM natural remanent magnetization; Dec: Declination of characteristic remanent magnetization (ChRM) direction; Inc: Inclination of ChRM direction; MAD: Maximum Angular Deviation; Q: quality index of ChRM direction, with 1 the highest quality and 2 the lowest; AF/Tinf: lowest AF level or temperature step of $\mathrm{ChRM}$ in $\mathrm{mT} /{ }^{\circ} \mathrm{C} ; \mathrm{AF} / \mathrm{Tsup}$ : highest $\mathrm{AF}$ level or temperature step of $\mathrm{ChRM}$ in $\mathrm{mT} /{ }^{\circ} \mathrm{C}$; Dir: ChRM direction Not anchored (NA) or anchored (A);VGP: Virtual Geomagnetic Pole latitude.

Extended Data Table 2. List and measurements of Daoxian teeth. List of the Daoxian dental remains by tooth class with the degree of occlusal wear (following Molnar,1971 ${ }^{36}$ ) crown measurements, and region and stratigraphic position (L: left; R: right; MD: mesiodistal diameter; BL: buccolingual diameter; Measurements are given in millimeters).

Extended Data Table 3. Comparative material. Detailed list of the samples included in the morphological and metric comparison. "*" means that we examined the original fossil. For the rest, we employed high resolution casts.

Extended Data Figure 5. Metric comparison of Daoxian teeth. Bivariate plots of the MD and BL diameters of UC, P3, M1, M2, M3, I2, M1 and M3 of Daoxian and comparative samples. 
Extended Data Figure 6. Morphological comparison of Daoxian teeth. Comparative morphology of the Daoxian human teeth with other Pleistocene hominins and modern humans. Upper left: Upper canines) I, V: Daoxian (DX37); II, VI: Xujiayao (PA1480); III, VII: Huanglong Cave; IV,VIII: modern human. Lower left: Upper third premolars) I, II, III: Daoxian (DX13, DX 29, DX42); IV: modern human, V: Chaoxian, VI: Changyang (PA76); VII: Panxian Dadong (PA1577); VIII: Xujiayao (PA1480). Upper right: Upper first molars) I: Daoxian (DX28); II: Neanderthal (Petit-Puymoyen Mx6); III: Qafzeh 5; IV: Tubo (PA1471); V: Hexian (PA836); VI: Chaoxian, VII: Xujiayao (PA1480); VIII: modern human. Middle right: Lower second molars) I: Daoxian (DX30); II: Dolni Vestonice (DV37); Neanderthal (Hortus IV); IV: Huanglong Cave, V: Xintai; VI: modern human. Lower right). Upper third molars: I,IV: Daoxian (DX17), II, VII: Xujiayao; III, VIII: Huanglong Cave; IV, IX: Tubo (PA1476); V, X: modern humans.

Extended Data Table 4. Upper first molar relative cusp and occlusal polygon areas. Data for Qafzeh and Late Pleistocene H. sapiens are taken from Bailey et al., $2008^{62}$ and Quam et al., $2009^{63}$. Late Pleistocene H. sapiens (LP HSAP) sample is composed by Dolni Vestonice, Fontechevade, Laugerie Basse, Les Rois, Madeleine, Mladec, Patud, St. Germaine-la-Rivière and Vachons. 


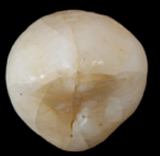

DX37-o

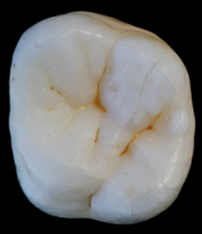

DX28-0

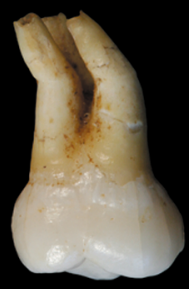

DX21-b

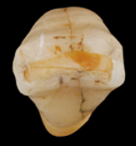

DX11-o
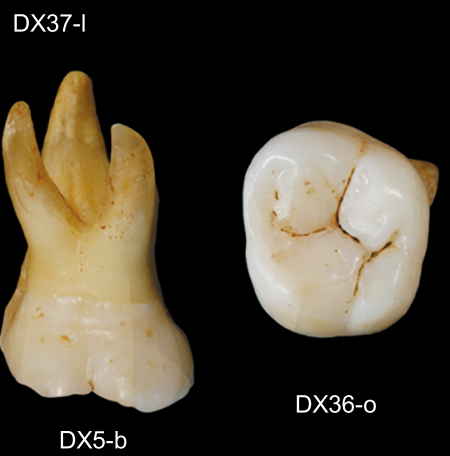

DX36-o

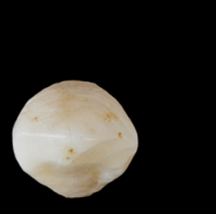

DX18-0

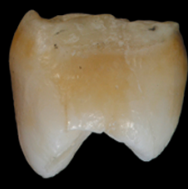

DX42-m
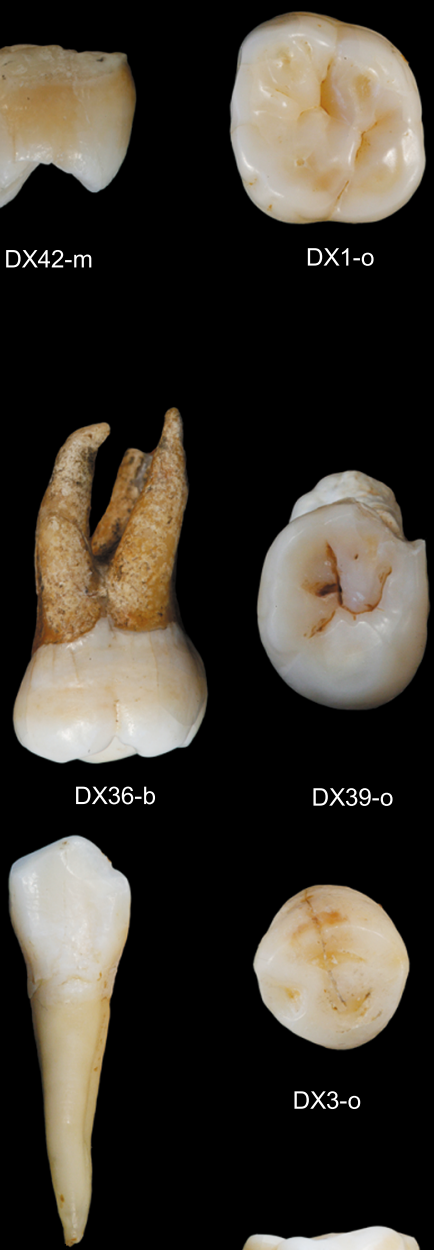

DX39-o

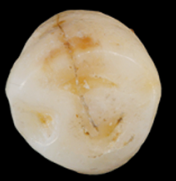

DX3-o

\section{DX18-I}
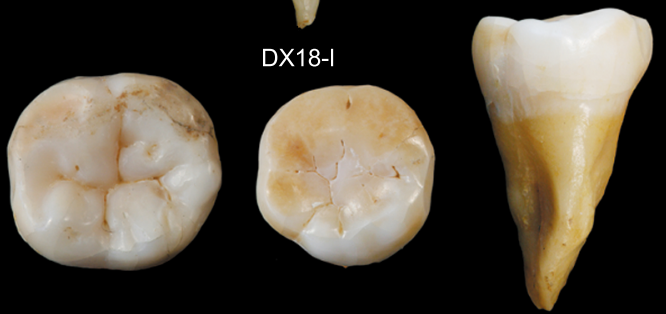

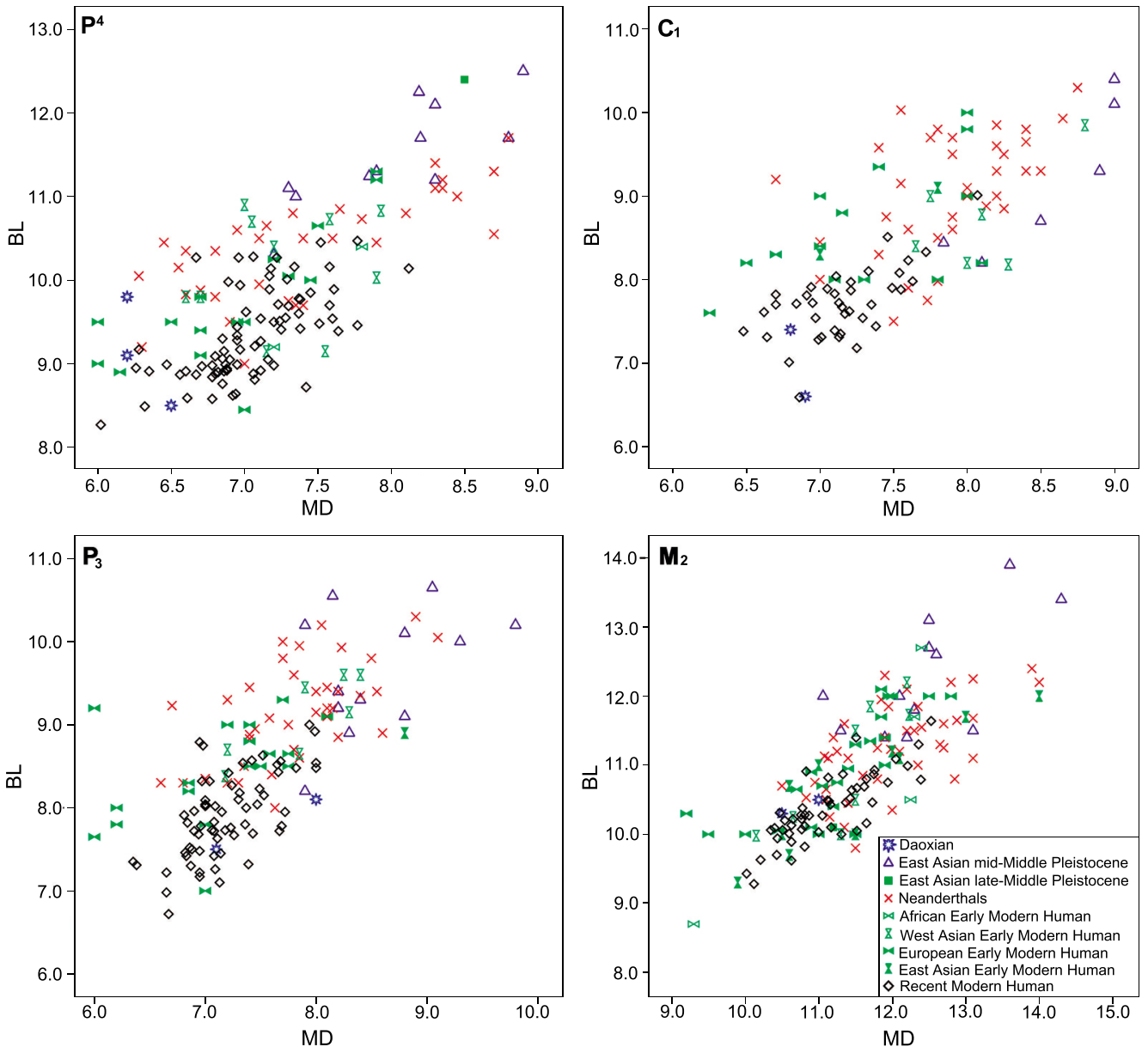